\title{
Downregulation of Col1a1 induces differentiation in mouse spermatogonia
}

\author{
Sun-Hong Chen, Ding Li and Chen Xu
}

Col1a1 (one of the subunit of collagen type I) is a collagen, which belongs to a family of extracellular matrix (ECM) proteins that play an important role in cellular proliferation and differentiation. However, the role of Col1a1 in spermatogenesis, especially in the control of proliferation and differentiation of spermatogonial stem cells (SSCs), remains unknown. In this study, we explored effects of downregulation of Col1a1 on differentiation and proliferation of mouse spermatogonia. Loss-of-function study revealed that Oct4 and PIzf, markers of SSC self-renewal, were significantly decreased, whereas the expression of c-kit and haprin, hallmarks of SSC differentiation, was enhanced after Col1a1 knockdown. Cell cycle analyses indicated that two-thirds of spermatogonia were arrested in S phase after Col1a1 knockdown. In vivo experiments, DNA injection and electroporation of the testes showed that spermatogonia self-renewal ability was impaired remarkably with the loss-of-function of Col1a1. Our data suggest that silencing of Col1a1 can suppress spermatogonia self-renewal and promote spermatogonia differentiation.

Asian Journal of Andrology (2012) 14, 842-849; doi:10.1038/aja.2012.66; published online 15 October 2012

Keywords: Col1a1; differentiation; extracellular matrix (ECM); spermatogenesis; spermatogonia

\section{INTRODUCTION}

Spermatogenesis is the process through which spermatogonial stem cells (SSCs) self-renew and differentiate into sperm. Spermatogenesis is composed of three particular phases: mitosis, meiosis and spermiogenesis. ${ }^{1}$ Previous studies have shown that spermatogenesis involves the detachment of spermatogonia from the basement membrane and their subsequent migration towards the lumen of seminiferous tubules. ${ }^{2,3}$

Although mechanisms underlying the maintenance and selfrenewal of SSCs have been explored by many research groups, ${ }^{1-3}$ the signaling molecules that mediate the decision of SSCs to differentiate rather than self-renewal remain largely unknown. The balance between self-renewal and differentiation of SSCs must be tightly controlled to maintain normal homeostasis in the normal seminiferous epithelium. If self-renewal prevails, the seminiferous tubule will be stem cells only and tumors might occur. ${ }^{4}$ More differentiation than self-renewal of SSCs would result in Sertoli cells only in the seminiferous epithelium, ${ }^{5}$ suggesting that there must be a regulatory mechanism controlling the ratio between self-renewal and differentiation of SSCs.

Increasing evidences have shown that stem cell development requires a niche, a local microenvironment that mediates the proliferation and differentiation of stem cells in tissues or organs. ${ }^{6-9}$ The extracellular matrix (ECM) as a major niche element provides not only a scaffold for cellular support, but also a source of signals directing stem cell self-renewal, differentiation, cell adhesion and cell migration. ${ }^{4}$ The ECM is a compound of matrix molecules which are typically large glycoproteins, including collagens, fibronectins, laminins and proteoglycans. ${ }^{10}$
Collagen I, a major ECM component, may be involved in the regulation of cellular differentiation. Loss of adhesion to ECM components (e.g. collagen I) induces terminal differentiation of keratinocytes, ${ }^{11}$ and collagen I mRNA was down-regulated during mesenchymal stem cell differentiation into chondrocyte-like cells. ${ }^{12}$ Type I collagen is also a dedifferentiation marker for human nasal chondrocytes and fetal bovine chondrocytes, and can be switched from collagen II and collagen IX during the proliferation of chondrocytes. ${ }^{13,14}$ Procollagen I, a precursor of type I collagen, is exclusively expressed in mouse undifferentiated spermatogonia but absent in the differentiated male germ cells, suggesting that procollagen I is associated with maintenance of $\mathrm{SSCs}^{15}$. However, the role of procollagen I in regulating SSC fate remains elusive. Two Colla1 chains and one Colla2 chain form procollagen I. The objective of this study was to elucidate the functional and developmental role of Colla1 during spermatogenesis. To this end, we performed a loss-of-function study of Colla1 in vitro to observe changes of molecular phenotype of SSCs. We then used an antisense strategy to knock down the expression of Colla1 in SSCs purified from 6-day-old mice. Here, we show the influence of Colla1 on the spermatogonia's proliferation and differentiation.

\section{MATERIALS AND METHODS}

Ethics statement

All experiments were conducted following the Guide for Care and Use of Laboratory Animals (the 'NIH Guide'). The protocols for the use of animals were approved by Department of laboratory animal sciences, Shanghai Jiao Tong University School of Medicine, with the permit number: SYXK/2008/0050. 


\section{Plasmids and other reagents}

The pDsRed2-1 and pAAV-IRES-hrGFP plasmids were gifts from Dr Lixin Feng (Shanghai Jiaotong University School of Medicine, China). Lipofection 2000 was purchased from Invitrogen (Carlsbad, CA, USA). T4 DNA ligase, restriction endonucleases Bgl II, Sal I, Not I and $B a m \mathrm{H}$ I were purchased from New England Biolabs (Beijing, China). Dulbecco's modified Eagle's medium (DMEM) was purchased from GIBCO BRL (Gaithersburg, MD, USA). PCR primers were synthesized by Shanghai Sangon Biological Engineering, Technology and Services (Shanghai, China). DNA sequencing was performed by Ding'an (Shanghai, China). Escherichia coli DH5 $\alpha$ was grown in LB containing $50 \mathrm{mg} \mathrm{l}^{-1}$ kanamycin.

\section{Construction of a targeting vector both carrying mouse Stra8 promoter and antisense fragment of Colla1}

The first step was to construct pStra8-Dsred2-1, a plasmid containing 580 bp fragment of Stra8 (NM_009292) promoter. The -550/ +29 fragment amplified from Stra8 genomic DNA was inserted into the $B g l$ II site of pDsred2-1 (Table 1 and Figure 1a and 1b). The second step was to construct pStra8-Dsred2-1-antisense Colla1, a plasmid containing an antisense fragment spanning the sequence of the first 1036 bp of Colla1 (NM_007742) (Table 1 and Figure 1c). The fragment amplified from testis cDNA was inserted into the $B g l \mathrm{II} / \mathrm{Sal} \mathrm{I}$ site of pDsred2-1, and the primers to amplify antisense of Collal containing Sal I site in the sense primer and $B g l$ II site in antisense primer were designed respectively (Table 2 ). The 580 bp Stra 8 promoter and pDsRed2-1 (a kind of promoterless vector) could direct the antisense transcript of Colla1. Finally, the fragment of pAAV-IRES-hrGFP between BamH I and Not I site was inserted into the vector as constructed above to displace the Bam $\mathrm{H}$ I/Not I site, and thus the recombinant vector, namely
pSPAPI, contains $3 \times$ FLAG, IRES, hrGFP and hGH pA (Figure 1d1f). The plasmid pSP, containing all the fragments of pSPAPI but antisense of Colla1, was served as a mock control.

\section{Isolation of mouse spermatogonia}

The decapsulated testes from 6-day-old male ICR mice were suspended in DMEM/F12 (Invitrogen) containing collagenase $(1.5 \mathrm{mg}$ $\left.\mathrm{ml}^{-1}\right)$ and DNAase $\left(1 \mu \mathrm{g} \mathrm{ml}^{-1}\right)$, and incubated at $34^{\circ} \mathrm{C}$ for $15 \mathrm{~min}$ in a shaking water bath operated at 100 cycles per min. After two washes in DMEM/F12 medium, seminiferous tubule fragments mostly devoid of interstitial cells were incubated in DMEM/F12 medium containing collagenase $\left(1.5 \mathrm{mg} \mathrm{ml}^{-1}\right)$, hyaluronidase $\left(1.5 \mathrm{mg} \mathrm{ml}^{-1}\right)$ and trypsin $\left(0.5 \mathrm{mg} \mathrm{ml}^{-1}\right)$ for 20-30 min using the method described above. The dispersed cells were washed twice with medium and through $80 \mu \mathrm{m}$ and $40 \mu \mathrm{m}$ nylon meshes respectively. The dispersed cells were incubated for 3-4 h, and then the Sertoli cells and peritubular myoid cells attached to the culture plates, while the spermatogonia still remained in suspension, which could be collected by centrifuging at $100 \mathrm{~g}$ for $5 \mathrm{~min}$. Six-day-old mice were chosen in this study because only Sertoli cells and spermatogonia (As, Apair and Aaligned spermatogonia) are present in the seminiferous epithelium at this age. ${ }^{16}$ The differential plating approach was used to separate spermatogonial populations from Sertoli cells and peritubular myoid cells, and the purity of the spermatogonia was $>90 \%$.

The spermatogenic capacity of the plasmid transfected cells were determined by flow cytometry, the transfected cells were stained with integrin $\beta 3$ antibody conjugated with phycoerythrin, $10 \mu \mathrm{l}$ for $10^{6}$ cells in $100 \mu \mathrm{l}$ solution, and the ratio of the cells with both green and red fluorescence to the cells with green fluorescence was analyzed. Flow cytometry analysis was repeated at least three times.

Table 1 Sequences of the insert fragment in reconstructed plasmids

Name

Upstream region of the Stra8 gene

Sequence of the fragments of Collal
Sequences

-550 tttgaggcgg aaaatgagtt gtagtccctc aacctggaga aaacttgttg cttactacaa

-490 acaactcaac acatcctctc tctctctctc ttttcttctc tgcattttaa gtccaccttt

-430 aaggttctct tctctgcttt tttagttggg aatcccctat tcccctctcc tattttgtac

-370 ctattccctc tcacatcttc attttctct ttcttttcct tgaaacaggg gactgctact

-310 gggaccttga agatggctcc tctatatctc aagagaaagt tataggtggc attgccetgg

-250 ttgaggggtg taagaactgg cgctagccgc ctggatgggg tgaaaaggtc atcttgctcc

-190 ttccacaccc tcttgcaacc tgtggcaagt tgttacaatg tttcaccaa tgtccacgct

-130 ccccattggc gccccaccat gcatccccat tggtcatggt ggcagtgaca gggctgtgat

-70 tggttcgcag cctggggtac caggtcagtt tttacctga ggcaagagcc tctcttcttc

-10 ttctgcgacg ggcagtcgtg agtgactgac tcgtcagggc

1 agacatgttc agctttgtgg acctccggct cctgctcctc ttaggggcca ctgccctcct

61 gacgcatggc caagaagaca tccctgaagt cagctgcata cacaatggcc taagggtccc

121 caatggtgag acgtggaaac ccgaggtatg cttgatctgt atctgccaca atggcacggc

181 tgtgtgcgat gacgtgcaat gcaatgaaga actggactgt cccaacccc aaagacggga

241 gggcgagtgc tgtgctttct gcccggaaga atacgtatca ccaaactcag aagatgtagg

301 agtcgaggga cccaagggag acctggccc ccaaggccca aggggacccg ttggcccccc

361 tggacgagat ggcatccetg gacagcctgg acttcctggt cctcctggtc cccetgggcc

421 ccccggaccc cctggccttg gaggaaactt tgcttcccag atgtcctatg gctatgatga

481 aaaatcagct ggagtttccg tgcctggccc catgggtcct tctggtcctc gtggtctccc

541 tggccccct ggtgcacctg gtccacaagg tttccaaggc ccccctggtg aacctggcga

601 gcctggcggt tcaggtccaa tgggtccccg aggtccccct ggccctcctg gcaagaatgg

661 agatgatggg gaagctggca agcccggccg tcctggtgag cgtggacctc ctggacctca

721 gggtgctcgt ggattgcctg gaacagctgg cctccctgga atgaagggac accgaggctt

781 cagtggtttg gatggtgcca aaggagatgc tggtcctgct ggtcctaagg gagagcccgg

841 cagtcctggt gaaaacggag ctcctggcca gatgggtccc cgaggtctgc ccggtgagag

901 aggtcgccct ggacctcctg gcactgctgg tgctcgcggt aacgatggtg ctgttggtgc

961 tgctggaccc cctggtccca ccggccccac tggccctcct ggcttccctg gtgcagttgg

1021 tgctaagggt gaagct 


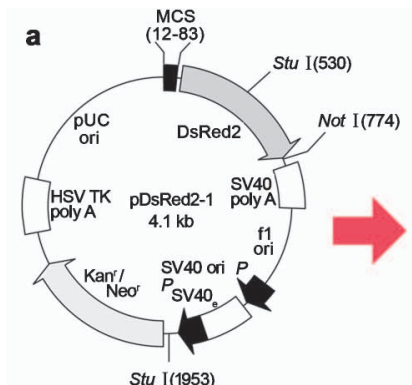

Stu I(1953)

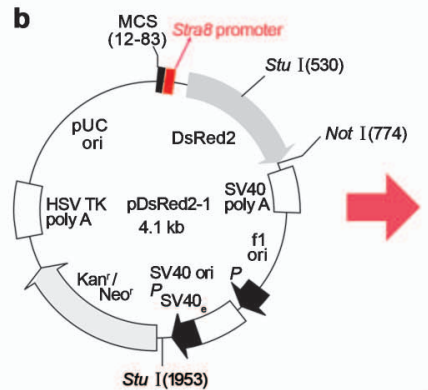

Stu I(1953)
C. MCS Strab promoter, anti-Coltat

(12-83) Strab promoler, anti-COlt
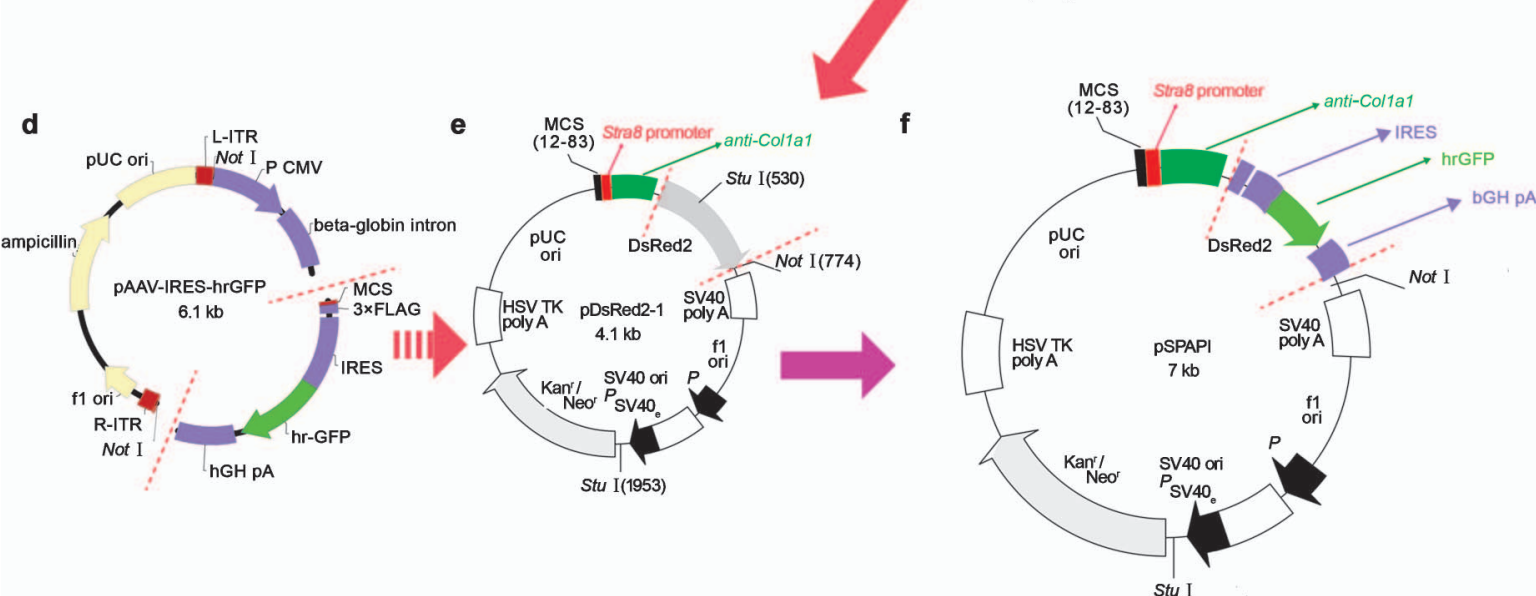

Figure 1 Construction of the pSPAPI plasmid carrying mouse Stra8 promoter, antisense DNA fragment of Colla1. The promoterless vector pDsred2-1 is a progenitor vector (a). The upstream region of the Stra8gene (from -550 to +29) was amplified and cloned into the Bg/ll site of the pDsred2-1 MCS (b), and thus, the vector could be transfected into spermatogonia specifically. A DNA fragment of Collal (from + 1 to +1036) containing enzyme site Sall in 5' end and enzyme site Bg/ll in 3' end respectively was then inserted into $B g / I I / S a / I$ site of the plasmid (c). pAAV-IRES-hrGFP was digested with BamH I and Not I, and then the fragment containing FLAG, Ires and hrGFP (d) took the place of the fragment of pDsred2-1 between the BamH I and Not I sites (e). Finally, the recombinant vector was designated as pSPAPI (f). MCS, multiple cloning site.

Table 2 Oligonucleotide primers used for RT-PCR

\begin{tabular}{|c|c|}
\hline Name & Sequences of primer \\
\hline \multirow[t]{2}{*}{ Stra8 promoter (from -550 to +29 ) } & F: 5'-ATAGATCTTTTGAGGCGGAAAATGAG-3' (containing Bg/II) \\
\hline & R: 5'-GGAGATCTGCCCTGACGAGTCAGTCACT-3' (containing Bg/II) \\
\hline Antisense sequence of procollagen I (from +1 to +1036 ) & F: 5'-TAAGTCGACAGACATGTTCAGCTTTGTGGACC-3' (containing Sal I) \\
\hline \multirow[t]{2}{*}{ Stra8 } & F: 5'-GCGGATCCCTCAAAGCATCCTTCAACCT-3' \\
\hline & R: 5'-GCAAGCTTTGGCGGCAGAGACAA AG-3' \\
\hline Oct4 & F: 5'-CACGAGTGGAAAGCAACTCA-3' \\
\hline Plzf & R: 5'-CTCCTGAGATGCTAGACTCAGCT-3' \\
\hline \multirow[t]{2}{*}{$c-k i t$} & F: 5'-CCCGACGCAACTTCCTTA-3' \\
\hline & R: 5'-CGCTTCTGCCTGCTCTTC-3' \\
\hline \multirow[t]{2}{*}{ Acrosin } & F:5'-CGGAGTCTACACAGCCACCT-3' \\
\hline & R:5'-GCATGAGTGATGAGGAGGTT-3' \\
\hline Haprin & F: 5'-CCAGAACATGAGACAGAGAG-3' \\
\hline Colla1 & R: 5'- ACGGGAATCCATCGGTCA-3' \\
\hline \multirow[t]{2}{*}{ Gapdh } & F: 5'-AAGGGCTCATGACCACAGTC-3' \\
\hline & R: 5'-ACACATTGGGGGTAGGAACA-3' \\
\hline
\end{tabular}




\section{Cell culture and transfection}

Mouse spermatogonia were cultured in DMEM/F12 (Invitrogen) supplemented with $10 \%$ fetal calf serum, penicillin $\left(100 \mathrm{U} \mathrm{ml}^{-1}\right)$ and streptomycin $\left(100 \mathrm{~g} \mathrm{ml}^{-1}\right)$ at $37^{\circ} \mathrm{C}$ in a humidified incubator with $5 \% \mathrm{CO}_{2}$. For the long-term maintenance of SSC potential, the isolated spermatogonia were cultured with Sertoli cells as feeder cells. Cells were counted and seeded onto $10-\mathrm{cm}$ dishes with $10^{7}$ cells per dish. After $12 \mathrm{~h}$ of culture, cells were transfected with the recombinant vector pSPAPI using Lipofection 2000 reagent, according to the manufacturer's manual. The transfected cells and supernatant were then harvested after $36 \mathrm{~h}$. Vector pSP was used as a mock. After $36 \mathrm{~h}$, the transfected primary spermatogonia with Sertoli cells were used for fluorescence-activated cell analysis sorting (FACS). Cell sorting was performed using a dual-laser fluorescence-activated cell sorter (FACS VantageSE; Becton Dickinson, San Jose, CA, USA). Cells showing green fluorescence were collected as positive cells.

\section{Reverse transcriptase-polymerase chain reaction (RT-PCR)}

Total RNA was isolated from the cultured cells using Trizol reagent (Invitrogen). The first-strand cDNA was synthesized using PrimeScript RT Reagent Kit (Takara). PCR was performed using specific primers (Table 2). House keeping gene, Gapdh, was used as an internal standard in all experiments. RT-PCR bands were quantified using Quantity One Softwere (Bio-Rad, Hercules, CA, USA), and the data were presented as mean \pm s.e.m. from three experiments. The mRNA transcript expressions of each gene were evaluated relative to the Gapdh expression in the individual samples and are presented as a ratio to that in controls.

\section{Western blotting}

Spermatogonia were transfected as described above and cell lysates were prepared in EBC buffer (50 mM Tris pH8, $170 \mathrm{mM} \mathrm{NaCl}, 0.5 \% \mathrm{NP} 40$, $50 \mathrm{mM} \mathrm{NaF}$ ) supplemented with protease inhibitors. Thirty micrograms of protein lysate per sample was denatured and fractionated by $10 \%$ SDS-PAGE. The separated proteins were transferred to a nitrocellulose membrane followed by blocking with $5 \%$ nonfat milk in TBS containing $0.1 \%$ Tween. Membranes were incubated for $2 \mathrm{~h}$ at room temperature with anti-procollagen I antibody $(1: 300)$ following which anti-rabbit IG conjugated with horseradish peroxidase at a $1: 2000$ dilution was used. The signals were detected with the Western Blotting Luminescent Reagent (Millipore, Billerica, MA, USA).

\section{Flow cytometry and analysis of cell ploidy}

The transfected spermatogonia were subjected to FACS using a FACS VantageSE apparatus at 24, 36 and $48 \mathrm{~h}$ respectively post-transfection. We assessed the proportion of cellular ploidy of testicular cells by staining with propidium iodide $\left(2 \mu \mathrm{g} \mathrm{ml}^{-1}\right)$ in the GFP-positive cells.

Cells were harvested using trypsin/EDTA solution ( $0.05 \%$ trypsin in $0.5 \mathrm{mmoll}^{-1}$ EDTA) and resuspended in PBS separately. For detection of the cell ploidy, testicular cells were stained with propidium iodide at a final concentration of $2 \mu \mathrm{g} \mathrm{ml}{ }^{-1}$ for $5 \mathrm{~min}$ at room temperature. Cell cycle distribution was determined by flow cytometry. Thousands of events were recorded for each sample and all analyzed events were gated to remove debris and aggregates. Cell cycle analysis was repeated at least three times.

DNA injection and electroporation of the testis

ICR mice were used for the in vivo DNA electroporation. Male mice $(n=5)$ at $20 \mathrm{dpp}$ were anesthetized with Nembutal solution. Testes were pulled out from the abdominal cavity, and approximately $15 \mu \mathrm{l}$ of plasmid DNA (10-15 $\mu \mathrm{g})$ solution were injected into the rete testis using glass capillaries under a binocular microscope. Within each mouse, left testis was injected with solution containing pDsRed2-1, while the right one was injected with pSPAPI. Electric pulses were delivered with an Electrosquare Porator ECM 830 Electro Square Porator (BTX, San Diego, CA, USA). Testes were directly held between a pair of tweezertrodes (BTX). Square electric pulses were applied three times, and again three times in the reverse direction at $50 \mathrm{~V}$ for $50 \mathrm{~ms}$ for each pulse.

\section{Histological examination}

In prepubertal mice, type A and type B spermatogonia are presented by day 8,2 days later, meiotic prophase is initiated. ${ }^{16,17}$ The testes were fixed 2 days after being electroporated with Bouin's solution, and were then embedded in paraffin preceded in two steps: dehydration and clearing. Paraffin blocks of testes were sectioned at a thickness of $5 \mu \mathrm{m}$. After being deparaffined, the sections were stained with hematoxylin and eosin. Images were taken with a microscope (Olympus, Tokyo, Japan) equipped with a CCD camera. Histology was compared between electroporated and control testes. At least three sections were examined per testis. Spermatogonia, Sertoli cells and primary spermatocytes within five seminiferous tubules each section were counted, respectively.

\section{Statistical analysis}

Statistical differences were assessed with $t$-test. Data are presented as mean \pm s.e.m., and $P$ values $<0.05$ were considered statically significant.

\section{RESULTS}

The Stra8 promoter used for directing spermatogonia-specific expression

To verify the cellular activity and specificity of the Stras promoter used, the primary cells (spermatogonia with Sertoli cells) after 36-h transfection with pSPAPI were analyzed for GFP expression using confocal laser scanning microscopy. Green fluorescence was observed only in spermatogonia (Figure 2), suggesting that the Stra8 promoter used specifically directed expression of the transgene (antisense Col1a1) in spermatogonia. However, only $\sim 10 \%$ spermatogonia were transfected by recombinant plasmid (Figure 2). Under the microscope, Sertoli cells were fibroblast-like and attached to the culture plates, while spermatogonia were round in shape in the suspension or adhered slightly to the plates. Flow cytometry analysis revealed that $\sim 93 \%$ of the GFP-positive cells were integrin-beta3 (marker for primordial germ cell ${ }^{18}$ ) positive, suggesting that the green cells were indeed spermatogonia.

\section{Levels of both Colla1 mRNAs and protein were reduced in mouse spermatogonia after the plasmid transfection}

RT-PCR and western blot analyses of mouse spermatogonia were performed $24 \mathrm{~h}$ and $48 \mathrm{~h}$, respectively after the cells were transfected with pSPAPI, and the cells transfected with pSP served as a mock control. Transfected cells were sorted and then proteins were extracted. In these experiments, both Collal mRNAs and protein was decreased significantly in the transfected spermatogonia (Figure 3), suggesting that the antisense transcripts of Colla1 indeed suppressed the transcription of the Collal in mouse spermatogonia.

\section{RT-PCR analysis for evaluation of differentiation}

To determine the effect of downexpression of Colla1, mouse spermatogonia were transfected with the recombinant plasmid pSPAPI. 

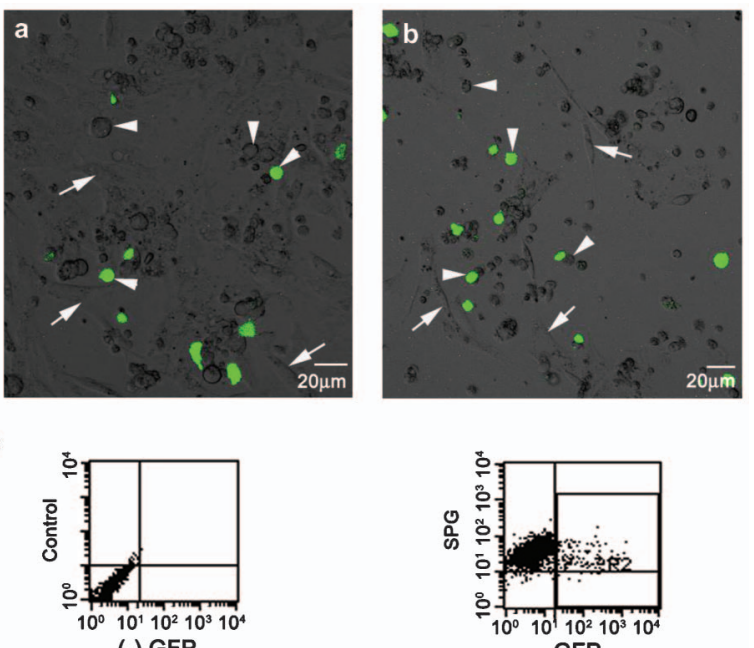

(-) GFP

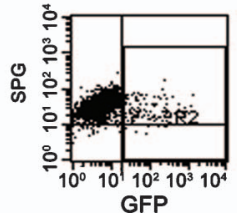

GFP

Figure 2 Identification of primary spermatogonia. Both spermatogonia and Sertoli cells, isolated from the seminiferous tubules of 6-day-old mice, were transfected with two recombinant plasmids respectively: pSP without the antisense of Colla1 fragment (a) and pSPAPI with the antisense of Collal (b). About $10 \%$ of spermatogonia (arrowhead) expressed GFP fluorescence, while Sertoli cells (arrow) were negative. Flow cytometry analysis revealed that $93 \%$ of the GFP-positive cells were integrin-beta3 (marker for primordial germ cell) positive, suggesting that the green cells were indeed spermatogonia (c). SPG, spermatogonia.

RT-PCR analyses were performed to quantify levels of several spermatogonial markers, including Oct4, Stra8, Pcna, Gfro-1 and Plzf. Levels of Pcna and Gfro-1 were downregulated slightly, Stra 8 remained stable, whereas Oct4, a marker of self-renewal spermatogonia, was almost completely silenced by Colla1 knockdown, and Plzf, a transcription factor for spermatogonial stem cell renewal, was downregulated in spermatogonia with knockdown of Colla1 (Figure 4a and 4b). We also analyzed the expression of some differentiation markers of spermatogonia, and observed upregulation of $c$-kit and Haprin, markers for differentiating spermatogonia. However, we could not detect Acrosin (Figure 4c and 4d).

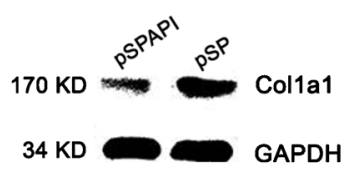

b

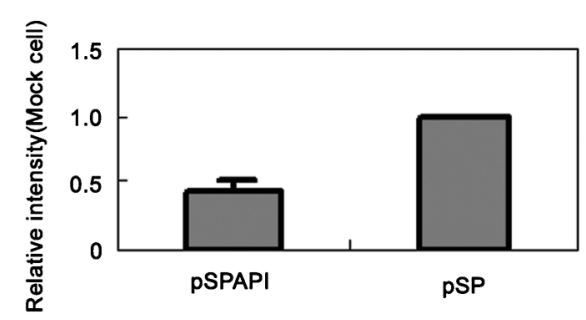

Figure 3 Colla1 knockdown assays in vitro. RT-PCR and western blotting were used to determine levels of Colla1 mRNA and protein. (a) Western blotting analyses of Colla1. (b) Quantification of Colla1 levels was shown with the standard deviations (s.d.). (c) Semiquantitative RT-PCR analyses of Colla1. Compared to the mock controls, levels of Colla1 in spermatogonia were significantly down regulated. Spermatogonia were transfected with pSPAPI or with pSP.
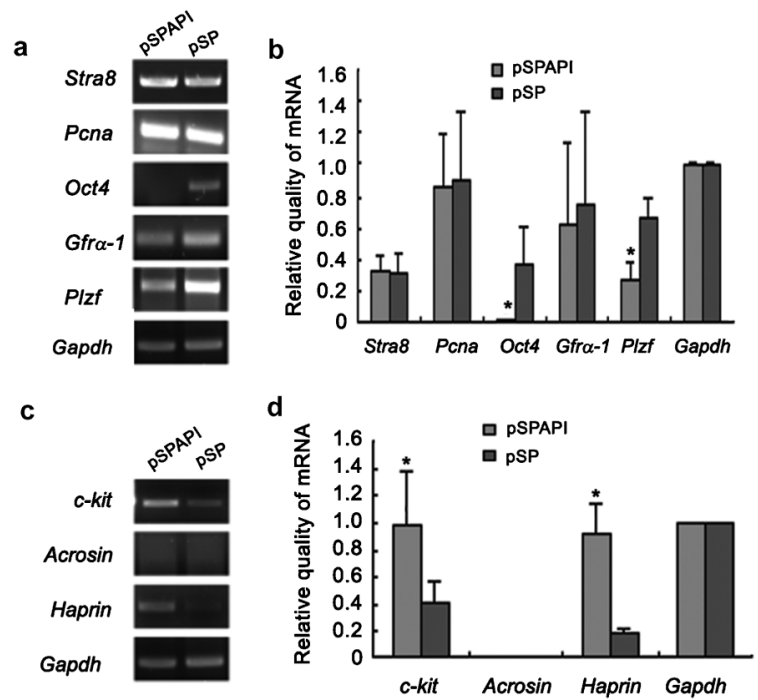

Figure 4 Levels of SSC marker genes in spermatogonia transfected by pSPAPI or pSP determined by semiquantitative RT-PCR analyses. Levels of Pcna and Gfr $\alpha-$ 1 were down-regulated slightly, while Stra8 remained stable, and Oct-4 expression was reduced to undetectable levels after antisense Colla 1 treatments (a, b). The expression of $c$-kit and haprin, two markers for spermatogonia differentiation, was upregulated after Collal knockdown (c, d). Gapdh served as a loading control. Bars represent abundance relative to Gapdh (b, d). Grey bars indicate mRNA in knockdown testes, while black ones represent mRNA in mock testes. Asterisk $(*)$ indicates statistical difference $(P<0.05)$. pSPAPI or pSP marked in the figure means that the cells were transfected by plasmid pSPAPI or plasmid pSP, respectively. SSC, spermatogonial stem cell.

\section{Cell cycle analyses in mouse spermatogonia after Col1a1 knockdown}

The cell cycle phase distribution of the plasmid transfected mouse spermatogonia was determined by flow cytometry. A representative cell cycle phase distribution of spermatogonia transfected with pSP and pSPAPI was shown in Figure 5. After 24 h, the experimental group (spermatogonia transfected with pSPAPI) showed $65.95 \% \pm 3.53 \%$ in $S$ phase, and $4.97 \% \pm 2.41 \%$ in G2 phase, while the mock group (spermatogonia transfected with pSP) displayed $40.12 \% \pm 0.98 \%$ in S phase and $25.13 \% \pm 1.86 \%$ in G2 phase, suggesting an increase in cells at $S$ phase, (Figure 5a-5c). Interestingly, after $36 \mathrm{~h}$ (Figure 5d-5f) and $48 \mathrm{~h}$ (Figure $5 \mathbf{g}-5 \mathbf{i}$ ), the cell cycle phase distribution of experimental groups appeared to be similar to that of the mock groups. These data suggest that knockdown of Col1a1 induced the S phase entry of spermatogonia, which is consistent with the decrease of the proportion of cells in G2 phase within $24 \mathrm{~h}$.

In vivo differentiation of spermatogonia after Colla1 knockdown Using the DNA electroporation protocol, we next examined effects of Colla1 knockdown on spermatogonial proliferation and differentiation in vivo. Testes electroporated with pSPAPI (expressing antisense Col1a1) and pSP (control) were collected and analyzed 2 days after electroporation. Histological analyses showed that the numbers of spermatogonia was reduced significantly in the seminiferous tubule (Figure 6e-6h), while the histology of control testes was similar to that of untreated testes (Figure $\mathbf{6 b}-\mathbf{6 d}$ ). The numbers of Sertoli cell did not differ $(P>0.05)$ between the Colla1 knockdown and control testes. Interestingly, the number of spermatogonia in Collal knockdown testes was about sevenfold fewer $(P<0.01)$ than that in mock testes. However, the number of primary spermatocyte in Colla1 knockdown 
a

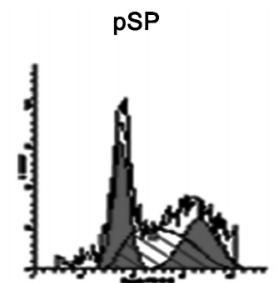

d

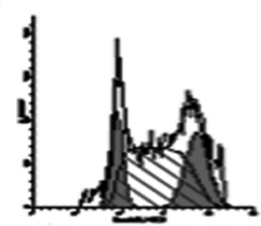

g

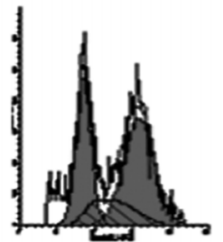

b
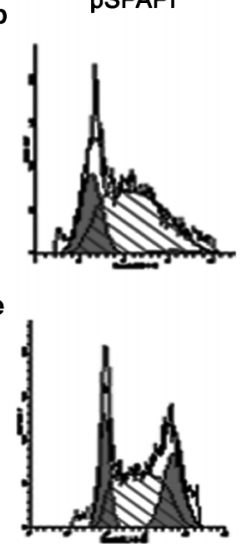

h

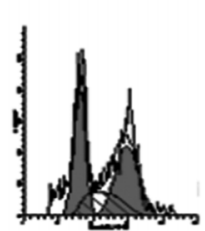

c

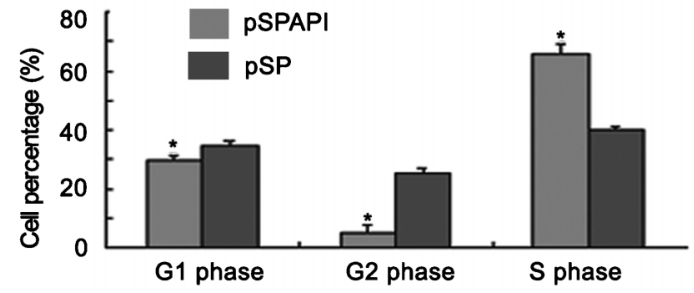

f
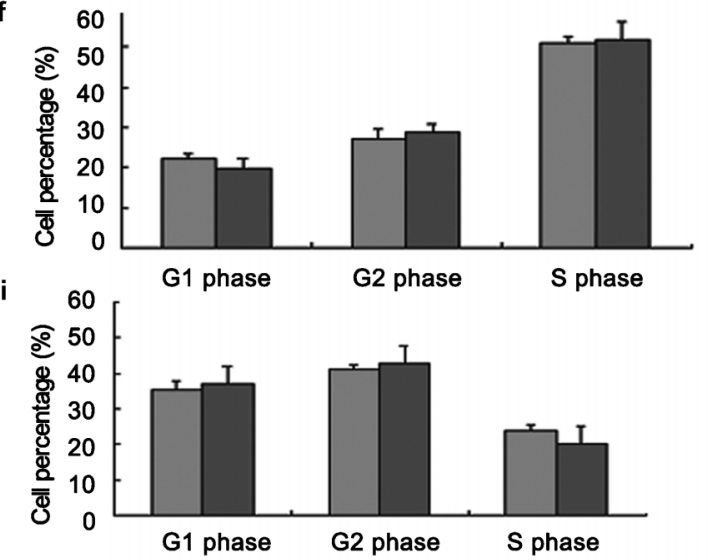

Figure 5 Cell cycle phase distribution of spermatogonia transfected with pSP and pSPAPI. Representative graphs showing the cell cycle phase (G1, G2 and S phase) distribution patterns in samples with and without Colla1 knockdown. An increase of cells in S phase and a decrease of cells in $\mathrm{G} 2$ phase were noticed in $24 \mathrm{~h}$ (a-c), but

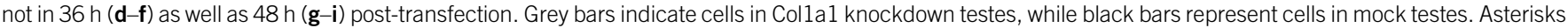
indicate statistical difference $(P<0.01)$. pSPAPI or pSP marked in the figure means that the cells were transfected by plasmid pSPAPI or plasmid pSP, respectively.

testes was about twice $(P<0.05)$ of the number seen in mock control testes (Figure 6i).

\section{DISCUSSION}

In this study, we investigated the potential role of Collal in spermatogonial self-renewal or differentiation. Our results revealed that a reduction in Colla1 mRNA and protein levels could lead to an imbalance between self-renewal and differentiation of spermatogonia, characteristic of suppressed self-renewal and accelerated differentiation. Therefore, Collal appears to be an important ECM component in maintaining normal spermatogonial homeostasis during spermatogenesis.

It is believed that $N$-propeptide region of collagens is important for its function. For example, the $\mathrm{N}$-propeptide region of procollagen IIA binds to TGF- $\beta 1$ and BMP-2, suggesting that the $\mathrm{NH}_{2}$-propeptide of procollagen IIA function in the ECM distribution of bone morphogenetic proteins during endochondral bone formation. ${ }^{19}$ Moreover, the $\mathrm{NH}_{2}$-propeptide of the cartilage-characteristic collagen, such as type II B, PIIBNP, is released into the ECM prior to formation of the collagen fibrils, and when it is suppressed by small interfering RNA, adhesion is blocked. ${ }^{20}$ Therefore, we chose the fragment (from +1 to +1036 bp) encoding the N-terminal of Collal for antisense-mediated gene knockdown study.

Stra8 is exclusively expressed in spermatogonia, ${ }^{21}$ rendering it a suitable promoter for directing transgene expression in all spermatogonia. Out data suggest that the $400 \mathrm{bp}$ fragment from the promoter region of Stra8 is sufficient for directing gene expression in spermatogonia, which is consistent with a previous report. ${ }^{22}$ Indeed, Stra8 promoter has been used to isolate spermatogonia including SSCs from the mouse testes. ${ }^{23}$

To demonstrate the functional importance of the Colla1 on spermatogonia self-renewal and differentiation, several gene markers were chosen for further analysis. When Colla1 levels were reduced, levels of markers for mouse spermatogonia and progenitors including Pcna, Gfro-1, Oct4 and Stra8, were changed in different way. Interestingly, Oct4, a hallmark for mouse SSCs, was reduced to undetected level in spermatogonia with the Colla1 knockdown (Figure 4), while levels of Gfr $\alpha-1$ was relatively lower compared to control cells and Pcna and Stra 8 change slightly. Pcna is expressed in proliferating spermatogonia and spermatocytes, but not in non-proliferating spermatogonia or preleptotene spermatocyte. ${ }^{24}$ Stra 8 is a vertebrate-specific gene whose expression is crucial for initiation of meiosis in both male and female germ cells ${ }^{25}$ and its overexpression is known to promote the in vitro differentiation of mouse embryonic stem cells into spermatozoa. ${ }^{21,26}$ Our observations suggest that in response to Collal suppression, the spermatogonial proliferation appeared to be suspended, while their differentiation was trigged. Supporting this notion, levels of $c$-kit, a hallmark for mouse differentiating spermatogonia, ${ }^{27,28}$ and Haprin, novel haploid germ cell-specific gene in the mouse potentially involved in the acrosome reaction, were upregulated. Acrosin is a marker of the acrosome in spermatids. It is a proteolytic enzyme that hydrolyses the zona pellucida (ZP) of the oocyte in the process of fertilization $^{29,30}$. Acrosin is expressed broadly in $1 \mathrm{~N}$ spermatid ${ }^{31}$. That is why we could not find Acrosin in the mock spermatogonia. The expression of Acrosin mRNA could not be detected in the transfected spermatogonia, suggesting that spermatogonia differentiated into early spermatocyte but not spermatid. Downregulation of Plzf, a transcription factor involved in spermatogonial stem cell renewal, ${ }^{32}$ is also supportive of the notion that Collal suppression can inhibit proliferation, but enhance differentiation. This effect was confirmed in vivo by electroporation-based gene delivery of Colla1 antisense mRNA-coding plasmids.

The seminiferous epithelium in the mammalian testis is segregated into the basal and the apical (adluminal) compartments by the 

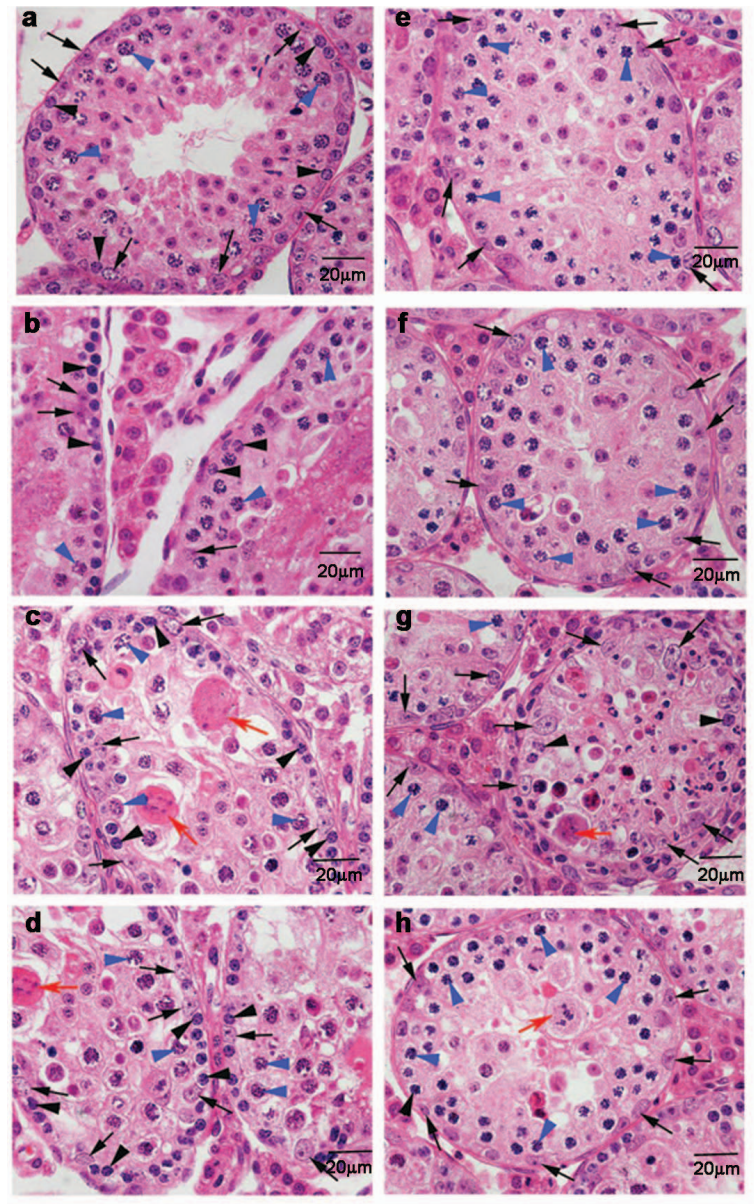

i

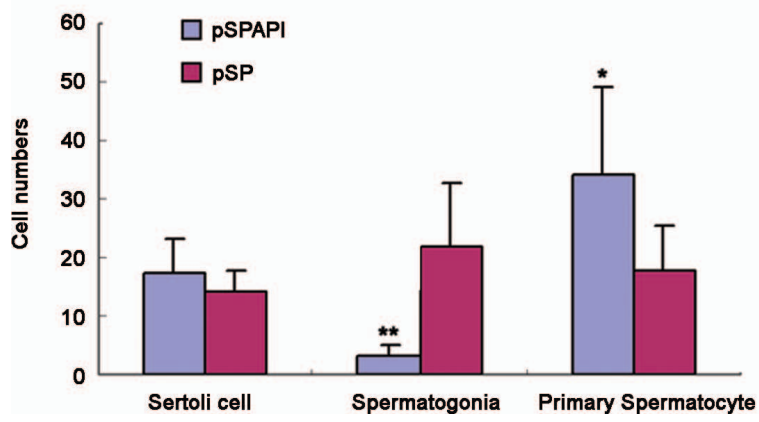

Figure 6 Morphology of the seminiferous tubule after electroporation. Knockdown of Colla1 could induce suppressed proliferation and accelerated proliferation of differentiation. Seminiferous tubule without electroporation displayed normal histology (a-d), whereas tubules electroporated with pSPAPI showed reduced number of spermatogonia (e-h). Mouse spermatogonia were indicated by black arrowhead, and spermatocytes were indicated by blue arrowhead. Sertoli cells were labeled by black arrows, while multinucleated giant cells were indicated by red arrows. Histograms show the number of three kinds of spermatogenic cell types per section in the knockdown and mock testes. Blue bars indicate cells in knockdown testes, while purple ones represent cells in mock testes (i). Asterisks indicate statistical difference $(P<0.05)$, and double asterisk $(* *)$ indicates statistical significant difference $(P<0.01)$. pSPAPI or pSP marked in the figure means that the cells were transfected by plasmid pSPAPI or plasmid pSP, respectively.

blood-testis barrier. ${ }^{33}$ Mitosis occurs in SSCs residing in the basal compartment to produce additional germ cells, some of which differentiate into type B spermatogonia and primary preleptotene spermatocytes. ${ }^{34,35}$ During their transit at the BTB, preleptotene spermatocytes differentiate into diplotene spermatocytes, and then enter metaphase I to undergo meiosis I and meiosis II which produces haploid spermatids in the apical compartment ${ }^{36,37}$. Collagen is one of the most abundant ECM proteins in basement membrane, and the basement membrane and integrins act as anchorage for undifferentiated spermatogonia. ${ }^{38}$ It has been shown that the de novo synthesis of collagens is associated with tight junction assembly. ${ }^{4}$ So we hypothesize that even the slightly restructuring in the basement membrane or cell junctions would disrupt the spermatogonia in undifferentiated state. The loss of the Collal in basement membrane might impair spermatogenesis, perhaps by disturbing cell-matrix interactions or by changing the structure of basement membrane and dynamics of cell junctions. Our data presented here also suggest that the balance of the self-renewal and differentiation in spermatogonia can be altered in response to Colla1 suppression. Progression of the cell cycle is precisely controlled by checkpoints, the signaling networks including ERK1/2 pathway that allows cells to monitor successive events and ensure ordered cell proliferation and genomic stability. ${ }^{39,40} \mathrm{He}$ et al. ${ }^{41}$ have showed that ERK1/2 pathway may be essential for the GDNFinduced G1/S transition in SSCs. GDNF signals through a multicomponent receptor complex comprised of Ret and Gfr $\alpha-1 .^{42,43}$ Our data have shown that Gfr $\alpha-1$ levels decreased slightly after Collal knockdown, suggesting that the ERK1/2 pathway may have been affected, leading to reduced interactions between GDNF with Gfr $\alpha-1$, and cell cycle arrest at the $S$ phase. But it is still unclear why the downregulation of Colla1 could affect the Gfr $\alpha-1$ expression.

In summary, our data suggest that Collal, as a component of the SSC niche, may play an important role in the control of the balance between SSC self-renewal and differentiation. Further study using conditional Colla1 knockout mice is needed for unequivocally establish such a role of Colla1.

\section{AUTHOR CONTRIBUTIONS}

SHC designed and performed the study, wrote the manuscript. DL performed the study. CX designed the study and wrote the manuscript.

\section{COMPETING FINANCIAL INTERESTS}

The authors have no competing financial interests to declare.

\section{ACKNOWLEDGMENTS}

We thank Dr Li-Xin Feng for advice on construction of plasmid. We also thank Dr Zuping He, Dr Jian-Qiang Bao, Dr Qiang Li, Dr Ying Hong and Dr Xue-Min Qian for reviewing the manuscript. This work was supported by grants from the Shanghai Municipal Education Commission (No. 10YZ45), Science and Technology Commission of Shanghai Municipality (No. 10DZ2270600), Shanghai Leading Academic Discipline Project (No. S30201) and Shanghai Basic Research Project (No. 09DJ1400400).

1 Cheng CY, Wong EW, Yan HH, Mruk DD. Regulation of spermatogenesis in the microenvironment of the seminiferous epithelium: new insights and advances. $\mathrm{Mol}$ Cell Endocrinol 2010, 315: 49-56.

2 Kostereva N, Hofmann MC. Regulation of the spermatogonial stem cell niche. Reprod Domest Anim 2008; 43 Suppl 2: 386-92.

3 Yoshida S, Sukeno M, Nabeshima Y. A vasculature-associated niche for undifferentiated spermatogonia in the mouse testis. Science 2007; 317: 1722-6.

4 Siu MK, Cheng CY. Extracellular matrix and its role in spermatogenesis. Adv Exp Med Biol 2008; 636: 74-91.

5 de Rooij DG. Proliferation and differentiation of spermatogonial stem cells. Reproduction 2001; 121: 347-54.

6 Schofield R. The relationship between the spleen colony-forming cell and the haemopoietic stem cell. Blood Cells 1978; 4: 7-25. 
7 Watt FM, Hogan BL. Out of Eden: stem cells and their niches. Science 2000; 287 1427-30.

8 Fuchs E, Tumbar T, Guasch G. Socializing with the neighbors: stem cells and their niche. Cell 2004; 116: 769-78.

9 Scadden DT. The stem-cell niche as an entity of action. Nature 2006; 441:1075-9.

10 Ma W, Tavakoli T, Derby E, Serebryakova Y, Rao MS et al. Cell-extracellular matrix interactions regulate neural differentiation of human embryonic stem cells. BMC Dev Biol 2008; 8: 90.

11 Adams JC, Watt FM. Changes in keratinocyte adhesion during terminal differentiation: reduction in fibronectin binding precedes alpha 5 beta 1 integrin loss from the cell surface. Cell 1990; 63: 425-35.

12 Chen G, Liu D, Tadokoro M, Hirochika R, Ohgushi H et al. Chondrogenic differentiation of human mesenchymal stem cells cultured in a cobweb-like biodegradable scaffold. Biochem Biophys Res Commun 2004; 322: 50-5.

13 Ronziere MC, Farjanel J, Freyria AM, Hartmann DJ, Herbage D. Analysis of types I, II, III, IX and XI collagens synthesized by fetal bovine chondrocytes in high-density culture. Osteoarthritis Cartilage 1997; 5: 205-14.

14 Malda J, van Blitterswijk CA, van Geffen M, Martens DE, Tramper J et al. Low oxygen tension stimulates the redifferentiation of dedifferentiated adult human nasal chondrocytes. Osteoarthritis Cartilage 2004; 12: 306-13.

15 He Z, Feng L, Zhang X, Geng Y, Parodi DA et al. Expression of Col1a1, Colla2 and procollagen I in germ cells of immature and adult mouse testis. Reproduction 2005; 130: 333-41.

16 Bellve AR, Cavicchia JC, Millette CF, O'Brien DA, Bhatnagar YM et al. Spermatogenic cells of the prepuberal mouse. Isolation and morphological characterization. J Cell Biol 1977; 74: 68-85.

17 Zindy F, den Besten W, Chen B, Rehg JE, Latres E et al. Control of spermatogenesis in mice by the cyclin D-dependent kinase inhibitors p18(Ink4c) and p19(Ink4d). Mol Cell Biol 2001; 21: 3244-55.

18 Hayashi K, Ohta H, Kurimoto K, Aramaki S, Saitou M. Reconstitution of the mouse germ cell specification pathway in culture by pluripotent stem cells. Cell 2011; 146: 519-32.

19 Zhu Y, Oganesian A, Keene DR, Sandell LJ. Type IIA procollagen containing the cysteine-rich amino propeptide is deposited in the extracellular matrix of prechondrogenic tissue and binds to TGF-beta1 and BMP-2. J Cell Biol 1999; 144 1069-80.

20 Wang Z, Bryan J, Franz C, Havlioglu N, Sandell LJ. Type IIB procollagen $\mathrm{NH}_{2}$ propeptide induces death of tumor cells via interaction with integrins alphavbeta and alphavbeta 5 . J Biol Chem 2010; 285: 20806-17.

21 Oulad-Abdelghani M, Bouillet P, Decimo D, Gansmuller A, Heyberger S et al. Characterization of a premeiotic germ cell-specific cytoplasmic protein encoded by Stra8, a novel retinoic acid-responsive gene. J Cell Biol 1996; 135: 469-77.

22 Giuili G, Tomljenovic A, Labrecque N, Oulad-Abdelghani M, Rassoulzadegan M et al. Murine spermatogonial stem cells: targeted transgene expression and purification in an active state. EMBO Rep 2002; 3: 753-9.

23 Guan K, Nayernia K, Maier LS, Wagner S, Dressel R et al. Pluripotency of spermatogonial stem cells from adult mouse testis. Nature 2006; 440: 1199-203.

24 He Z, Kokkinaki M, Jiang J, Dobrinski I, Dym M. Isolation, characterization, and culture of human spermatogonia. Biol Reprod 2010; 82: 363-72.
25 Anderson EL, Baltus AE, Roepers-Gajadien HL, Hassold TJ, de Rooij DG et al. Stra8 and its inducer, retinoic acid, regulate meiotic initiation in both spermatogenesis and oogenesis in mice. Proc Natl Acad Sci USA 2008; 105: 14976-80.

26 Nayernia K, Nolte J, Michelmann HW, Lee JH, Rathsack K et al. In vitro-differentiated embryonic stem cells give rise to male gametes that can generate offspring mice. Dev Cell 2006; 11: 125-32.

27 He Z, Jiang J, Hofmann MC, Dym M. Gfral silencing in mouse spermatogonial stem cells results in their differentiation via the inactivation of RET tyrosine kinase. Biol Reprod 2007; 77: 723-33.

28 Yoshinaga K, Nishikawa S, Ogawa M, Hayashi S, Kunisada T et al. Role of c-kit in mouse spermatogenesis: identification of spermatogonia as a specific site of c-kit expression and function. Development 1991; 113: 689-99.

29 Adham IM, Nayernia K, Engel W. Spermatozoa lacking acrosin protein show delayed fertilization. Mol Reprod Dev 1997; 46: 370-6.

30 Lax $Y$, Rubinstein S, Breitbart H. Acrosin activity assay for the evaluation of mammalian sperm acrosome reaction. Methods Mol Biol 2004; 253: 135-40.

31 Panula S, Medrano JV, Kee K, Bergstrom R, Nguyen HN et al. Human germ cell differentiation from fetal- and adult-derived induced pluripotent stem cells. Hum Mol Genet 2010; 20: 752-62.

32 Filipponi D, Hobbs RM, Ottolenghi S, Rossi P, Jannini EA et al. Repression of kit expression by Plzf in germ cells. Mol Cell Biol 2007; 27: 6770-81.

33 Cheng CY, Mruk DD. Cell junction dynamics in the testis: Sertoli-germ cell interactions and male contraceptive development. Physiol Rev 2002; 82: 825-74.

34 de Kretser DM, Kerr JB. The effect of testicular damage on Sertoli and Leydig cell function. Monogr Endocrinol 1983; 25: 133-54.

35 Sharpe RM, Kerr JB, McKinnell C, Millar M. Temporal relationship between androgendependent changes in the volume of seminiferous tubule fluid, lumen size and seminiferous tubule protein secretion in rats. J Reprod Fertil 1994; 101: 193-8.

36 Parvinen M. Regulation of the seminiferous epithelium. Endocr Rev 1982; 3: 404 17.

37 Hess RA, Renato de Franca L. Spermatogenesis and cycle of the seminiferous epithelium. Adv Exp Med Biol 2008; 636: 1-15.

38 Shinohara T, Avarbock MR, Brinster RL. Beta1- and alpha6-integrin are surface markers on mouse spermatogonial stem cells. Proc Natl Acad Sci USA 1999; 96: 5504-9.

39 Chow JP, Siu WY, Ho HT, Ma KH, Ho CC et al. Differential contribution of inhibitory phosphorylation of CDC2 and CDK2 for unperturbed cell cycle control and DNA integrity checkpoints. J Biol Chem 2003; 278: 40815-28.

40 Petermann E, Caldecott KW. Evidence that the ATR/Chk1 pathway maintains norma replication fork progression during unperturbed S phase. Cell Cycle 2006; 5: 2203-9.

41 He Z, Jiang J, Kokkinaki M, Golestaneh N, Hofmann MC et al. Gdnf upregulates c-Fos transcription via the Ras/Erk1/2 pathway to promote mouse spermatogonial stem cell proliferation. Stem Cells 2008; 26: 266-78.

42 Jing S, Wen D, Yu Y, Holst PL, Luo Y et al. GDNF-induced activation of the ret protein tyrosine kinase is mediated by GDNFR-alpha, a novel receptor for GDNF. Cell 1996; 85: 1113-24.

43 Treanor JJ, Goodman L, de Sauvage F, Stone DM, Poulsen KT et al. Characterization of a multicomponent receptor for GDNF. Nature 1996; 382: 80-3. 